\title{
VALIDATION OF CLONAL LINE FEMALES FOR SEX DETERMINATION STUDIES IN NILE TILAPIA Oreochromis niloticus $\mathrm{L}$.
}

\section{Mohd Golam Quader Khan ${ }^{1 *}$, Brendan J McAndrew and David J Penman}

Institute of Aquaculture, University of Stirling, Stirling FK9 4LA, Scotland, UK, ${ }^{1}$ Department of Fisheries Biology and Genetics, Bangladesh Agricultural University, Mymensingh-2202, Bangladesh

*Corresponding author: Mohd Golam Quader Khan, E-mail: khanmgq@yahoo.com

\begin{tabular}{|c|c|}
\hline ARTICLE INFO & ABSTRACT \\
\hline $\begin{array}{l}\text { Received } \\
08.11 .2014 \\
\text { Accepted } \\
14.12 .2014 \\
\text { Online } \\
27.12 .2014 \\
\text { Key words: } \\
\text { Clonal line } \\
\text { Microsatellite } \\
\text { marker } \\
\text { Sex } \\
\text { Nile tilapia } \\
\text { Oreochromis } \\
\text { niloticus }\end{array}$ & $\begin{array}{l}\text { Sex determination in the Nile tilapia Oreochromis niloticus is more } \\
\text { complex than a simple XX-XY sex determining mechanism, as evidenced } \\
\text { from fairly frequent unexpected sex ratios in progeny. The production of } \\
\text { uniform, homozygous experimental material is particularly advantageous } \\
\text { for studying sex determining mechanism as well as for the genetic } \\
\text { mapping and genome sequencing studies in which interpretations are } \\
\text { facilitated by homozygosity. To better understand the genetic mechanism } \\
\text { of sex determination, a fully inbred line of clonal females (XX) was verified } \\
\text { in controlled environmental conditions using test crosses and } \\
\text { microsatellite DNA markers from the tilapia linkage map. A total of } \\
\text { successfully amplified } 87 \text { microsatellite DNA markers covering all } 24 \\
\text { linkage groups were selected for screening sexually mature females from } \\
\text { this line. } 67 \text { markers were found polymorphic in outbred individuals } \\
\text { screened. Markers from LG1, LG3 and LG23 were given more emphasis } \\
\text { because sex determining genes have been mapped on these LGs in } \\
\text { different species of tilapia. The verification and validation of this clonal line } \\
\text { of females made them an important resource to use as a 'standard } \\
\text { reference line' in genomics, sex determination studies and other studies in } \\
\text { Nile tilapia. }\end{array}$ \\
\hline
\end{tabular}

To cite this article: MGQ Khan, BJ McAndrew and DJ Penman, 2014. Validation of clonal line females for sex determination studies in Nile tilapia Oreochromis niloticus L. Res. Agric., Livest. Fish. 1(1): 147-158.

This article is an open access article licensed under the terms of the Creative Commons Attribution License. 


\section{INTRODUCTION}

Clonal individuals play a significant and expanding role in many scientific disciplines, including biomedicine, genomics, toxicology, immunology and evolutionary biology (Trevarrow and Robinson, 2004). Fish species that have external fertilization can be reproduced (cloned) by induced parthenogenesis, e.g., androgenesis or "mitotic" gynogenesis (techniques reviewed by Dunham 2004; Komen and Thorgaard, 2007) that may result in clonal individuals or novel genotypes (such as YY males or WW females). The nuclear content of either the sperm or egg is destroyed by UV or gamma irradiation, and the treated gamete then is fused with an untreated egg or sperm to form a haploid embryo. The haploid embryo, which is a good resource for genemapping (being equivalent to large single gametes that contain enough DNA for gene-mapping purposes; Kocher et al., 1998), will continue to develop but will normally die before hatching. However, it is possible to make the embryo diploid by inhibition of the second meiotic division ("meiotic" gynogenesis); such individuals retain a duplicated set of chromosomes from the untreated gamete but are not completely homozygous. Meiotic gynogenetic offspring are on average homozygous at $50 \%$ of the loci that were heterozygous in the mother because they retain a pair of sister chromatids, which have undergone recombination (Purdom, 1969; Nace et al., 1970; Allendorf and Leary, 1984; Hussain et al., 1994). If the shock is given later, the first or the second mitotic division is suppressed (in mitotic gynogenesis or androgenesis) and two haploid copies of the maternal or paternal chromosomes respectively are retained to produce double haploid or dihaploid offspring. These offspring carry only the duplicated set of chromosomes and are, by definition, fully homozygous individuals. The dihaploids should be homozygous at all loci but different individuals originating from the same outbred parent will be fixed for different alleles at any given locus depending on the recombination events that generated that gamete. These dihaploid individuals from either a gynogenetic or androgenetic background can be used to generate clonal or isogenic lines as all gametes produced by such an individual will be identical, even after recombination (barring any mutation, which is expected to be very infrequent). When these gametes are used in a second round of induced parthenogenesis, all of the offspring will be identical (clonal). Mitotic or meiotic gynogenesis, or androgenesis may be used in this second round (Hussain et al., 1998) to advance the line. It is therefore possible to generate clonal lines in as little as two generations for any particular species or strain of fish. However, it may be easier to hormonally sex reverse a proportion of the fish within a line to obtain both sexes (second generation or later), which then allows the line to be propagated by simple crosses.

In Nile tilapia, completely homozygous gynogenetic individuals were produced by using irradiated sperm and suppressing the first or second (Zhang and Onozato, 2004) mitotic division using late heat shock (at temperature $42-42.5{ }^{\circ} \mathrm{C}$ ) starting at 27-29 minutes after fertilization (Müller-Belecke and Hörstgen-Schwark, 1995; Hussain et al., 1998; Sarder et al., 1999). Firstgeneration clonal $O$. niloticus and an outbred clonal group were produced by crossing between a mitotic gynogenetic female and a mitotic gynogenetic male in the Stirling Nile tilapia population (Hussain et al., 1998; Sarder et al., 1999). Since then, clonal lines of females have been produced by i) either mitotic gynogenesis or meiotic gynogenesis from mitogyne individuals (clone founders homozygous females) and by ii) hormonally sex reversing a proportion of the fish within a line to obtain both sexes, and crossing them to produce and advance homozygous line at the Tropical Aquarium Facilities (TAF), Institute of Aquaculture, Stirling. The clonal line used in the present experiments is one of the lines produced by Ezaz et al. (2004b) verified using a few AFLP markers. The current study exploits fairly a large number of microsatellite markers for the verification of the inbred individuals since they are important material for genome sequence and sex determination studies.

Production of uniform, homozygous experimental material is particularly advantageous for many genetic mapping and genome sequencing studies in which interpretations are facilitated by homozygosity. Large-scale BAC (bacterial artificial chromosome) fingerprinting and sequencing can benefit when variation due to allelic heterozygosity is eliminated by using homozygous clonal material (Wayne and Mclntyre, 2002). The current sequencing of the Nile tilapia and Atlantic salmon genomes is based on the clonal line and mitogynes respectively (Liu, 2007). In sex ratio studies, clonal lines play a highly advantageous role for example as reference strains and constant factors in crosses to analyse sex-determination mechanism. Any genetic variation acquired by the 
offspring is attributable to the individuals with whom the clonal animals are mated. This knowledge of sex determination is useful in improving monosex production for control of reproduction in Nile tilapia (Beardmore et al., 2001).

Once putative gynogenetics or androgenetics have been obtained, it is important to determine the success of the procedure to avoid contamination in setting up homozygous lines. Phenotypic (morphological) markers can be used if the trait is based on a recessive allele (Galbusera et al., 2000) and such characteristics have been used to assess inheritance in gynogenetic fish such as common carp (Nagy et al., 1978) and tilapia (Don and Avtalion, 1988; Varadaraj 1990; Myers et al., 1995). However, such morphological markers are rare (Ezaz et al., 2004a), and confirmation using biochemical or molecular markers is required to allow the unambiguous identification of inheritance. The screening for homozygosity at greater number of loci with large number of genetic markers should allow more accurate verification of gynogenetic clonal females.

Genetic markers can provide evidence on whether diploid gynogenesis results from a blockage of the first or second mitotic division, or from a blockage of polar body extrusion. Biochemical markers such as allozyme loci have been used to evaluate the success of gynogenesis in tilapia (Hussain et al., 1998; Sarder et al., 1999). Multilocus DNA fingerprinting has been used in several fish species including tilapia (Carter et al., 1991; Muller-Belecke and Horstgen-Schwark, 1995), African catfish (Volckaert et al., 1994) and sea bass (Felip et al., 2000). RFLP (Restriction Fragment Length Polymorphism), RAPD (Random amplified polymorphic DNA) and simple sequence repeat-anchored PCR (SSRa-PCR) have also been useful to study the clonal status of clone founders and to examine the uniformity of the gynogenetic offspring of founders and the genetic differences among the clones (Jenneckens et al., 1999; Galbusera et al., 2000; Peruzzi and Chatain, 2000).

Microsatellite DNA markers could be a proper tool to investigate the homozygous nature of clonal line fish. They have a number of desirable properties, including high polymorphism and consequently high information content, and ease of amplification (Vignal et al., 2002). Polymorphic microsatellite markers are very useful in identifying the minor genetic variation in population. They can detect and compare polymorphism between clonal and outbred animals, identify loci with high gene-centromere recombination rates in meiotic gynogenetics which can be used to discriminate meiotic from mitotic gynogenetics (Ezaz et al., 2004b), and can serve as unique 'identifiers' of clonal lines. The present study was performed to verify fully inbred females of a clonal line (previously developed by gynogenesis) using microsatellite DNA markers from across the tilapia genome, and to validate the line as a reference line for studies on sex determination of Nile tilapia. The specific objectives were to screen for marker homozygosity at loci across the genome and observation the progeny sex ratio clonal line females $\mathrm{x}$ clonal neomales.

\section{MATERIALS AND METHODS}

\section{Fish Stock}

A number of fully inbred clonal lines of $O$. niloticus were produced previously by gynogenesis (Sarder et al., 1999; Ezaz et al., 2004b). Many of these showed low fertility. One XX line that showed good fertility was maintained in the Tropical Aquarium Facilities, Institute of Aquaculture, University of Stirling and the line advanced through breeding of clonal females and clonal neomales (the latter produced by hormonal masculinisation).

Six sexually mature females from this inbred line were selected for the study. Each of the females was tagged with a passive integrated transponder (PIT) tag and kept in a glass tank. Six outbred females were also reared to be used for comparison of sex ratios with clonal females for a range of males. The basic maintenance of the experimental stock rigorously followed working procedures under ASPA (Animals Scientific Procedures Act, 1986) and monitored by the Home Office in the United Kingdom.

\section{DNA extraction and quantification}

DNA was extracted from fin clips using the REAL kit method (REAL laboratory, Spain) and quantified with a Nanodrop spectrophotometer (Thermo Fisher Scientific, USA). 


\section{Selection of DNA markers}

DNA markers were selected from the tilapia linkage map (Lee et al., 2005). Markers were chosen to be approximately evenly spaced from each linkage group to cover the whole genome. A total of 93 microsatellite DNA markers covering all 24 LGs were selected for this study (Table 1). The number of markers per LG ranges from one to six depending on the size of LG. Markers from LG1, LG3 and LG23 were given more emphasis in selection criteria $(n=26)$ because sex determining genes have been mapped on these LGs in different species of tilapia (Lee et al., 2003, 2004; Shirak et al., 2006).

Table 1. Selected microsatellite markers from tilapia linkage map for amplifying DNA

\begin{tabular}{|c|c|c|}
\hline $\begin{array}{l}\text { Linkage } \\
\text { group }\end{array}$ & Name of markers & $\begin{array}{l}\text { No. in } \\
\text { each LG }\end{array}$ \\
\hline 1 & $\begin{array}{l}\text { GM633, UNH985, UNH931, UNH213, GM201, UNH148, UNH995, UNH104, } \\
\text { GM258, UNH719, UNH846 }\end{array}$ & 11 \\
\hline 2 & GM420, GM096, UNH860, UNH854, UNH159 & 5 \\
\hline 3 & GM354, GM271, UNH971, GM150, GM128, GM526, UNH982 & 7 \\
\hline 4 & GM470, UNH124, UNH170, GM553 & 4 \\
\hline 5 & UNH817, UNH884, UNH309, UNH980 & 4 \\
\hline 6 & UNH948, UNH908, UNH968, GM440 & 4 \\
\hline 7 & GM205, UNH899 & 2 \\
\hline 8 & GM027 & 1 \\
\hline 9 & UNH843, UNH886, GM343, UNH132, GM062 & 5 \\
\hline 10 & UNH994, UNH960, GM080, GM472 & 4 \\
\hline 11 & UNH990, UNH192, GM215, GM399, UNH878, UNH979 & 6 \\
\hline 12 & GM377, UNH874, UNH1009 & 3 \\
\hline 13 & GM373, UNH954 & 2 \\
\hline 14 & GM070, GM665, UNH885 & 3 \\
\hline 15 & GM664, UNH880, GM129 & 3 \\
\hline 16 & GM056, GM168, UNH176 & 3 \\
\hline 17 & UNH103, UNH974, UNH440 & 3 \\
\hline 18 & UNH904, UNH888, GM285 & 3 \\
\hline 19 & UNH419, UNH943, UNH844, & 3 \\
\hline 20 & UNH174, UNH866, GM363 & 3 \\
\hline 21 & UNH957, GM221 & 2 \\
\hline 22 & GM531, UNH905, UNH840 & 3 \\
\hline 23 & GM557, UNH848, UNH197, GM597, UNH898, UNH879, GM576, UNH907 & 8 \\
\hline 24 & GM173 & 1 \\
\hline
\end{tabular}

\section{DNA amplification}

Polymerase chain reaction of the quantified DNA from clonal females was carried out in $15 \mu \mathrm{l}$ reaction mixtures, using three different "tailed" fluorescent primers to label the PCR products. The components used for a single reaction mixture are 1X Reaction buffer, $1.5 \mathrm{mM} \mathrm{MgCl}, 0.2 \mathrm{mM}$ of dNTPs, $0.3 \mu \mathrm{M}$ Labeled primer, $0.3 \mu \mathrm{M}$ FW/RV primer, $0.02 \mu \mathrm{M}$ Tailed primer, $0.05 \mathrm{U} / \mu \mathrm{l}$ and $0.05 \mu \mathrm{g}$ to $1 \mu \mathrm{g}$ template DNA. The thermocycler conditions varied for the different fluorescent primers: M13 blue (ggataacaatttcacacagg), CAG tag green (cagtcgggcgtcatca) and Godde black (catcgctgattcgcacat). The forward and reverse sequences of the primers were retrieved from the $\mathrm{NCBI}$ databank and any one of the three fluorescent sequences (blue or green or black) was added at 5' end of either the forward or of the reverse primer, thus that primer was the 'tailed' primer.

The annealing temperatures for markers from LG1, LG3 and LG23 were determined from saltadjusted and base stacking melting temperatures (Mueller et al., 1994; Santalucia, 1998) and used in PCR (Table 3) with some modifications. PCR was performed at $95^{\circ} \mathrm{C}$ for $14 \mathrm{~min}$ followed by 40 cycles of $95^{\circ} \mathrm{C}$ for $1 \mathrm{~min}$, one or two-step annealing temperatures (Table 3) for markers from LG1, 3 and $23,72^{\circ} \mathrm{C}$ for $1 \mathrm{~min}$, with a final elongation step of $72{ }^{\circ} \mathrm{C}$ for $30 \mathrm{~min}$. For the rest of the markers, annealing temperatures of $57^{\circ} \mathrm{C}, 58^{\circ} \mathrm{C}$ and $60^{\circ} \mathrm{C}$ were used for tailed primers having $\mathrm{M} 13$ blue, CAG tag green and Godde black, respectively. 


\section{Genotyping and fragment analyses}

The labeled PCR fragments were genotyped using the CEQ ${ }^{T M} 8800$ capillary sequencer to observe the specific allele makeup of the individuals with reference to a specific character (i.e., sex) under consideration. For each capillary run, $0.9 \mu \mathrm{l}$ product of single PCR reaction was added into a 96 well sequencer plate (Beckman Coulter $®$,USA) containing $30 \mu \mathrm{l}$ SLS (Sample Loading Solution) and $0.25 \mu \mathrm{l}$ DNA Size Standard kit-400 (SS400, Beckman Coulter $囚, U S A)$ containing fragments labeled with D1-red dye. One drop of mineral oil was added on the top of each sample. An electrophoresis buffer tray, 96 well plate with flat bottom (Beckman Coulter $\AA$, USA), was prepared. Each row of 8 samples ran for 45 min using Beckman Frag-3 genotyping method.

\section{Evaluation of sex ratios between clonal females and sex-reversed neomales}

Once the clonal nature of the females was determined, sex ratios were observed in crosses between females and neomales (hormonally masculinized XX individuals) within this line. A total of 8 crosses were performed, four neomales each crossed to two females, with six different females involved. The survival rates in clonal line progeny were also compared with those in outbred groups on day 11, after the completion of yolk sac absorption period.

Table 2. Annealing temperatures for markers from LG1, LG3 and LG23 used in PCR

\begin{tabular}{|c|c|c|}
\hline LG & Marker & Annealing temperatures used in PCR cycles \\
\hline \multirow[t]{11}{*}{1} & GM633 & 2 cycles at 65,38 cycles at 60 \\
\hline & UNH985 & 2 cycles at 64,38 cycles at 60 \\
\hline & UNH931 & 2 cycles at 64,38 cycles at 57 \\
\hline & UNH213 & 2 cycles at 65,38 cycles at 58 \\
\hline & GM201 & 2 cycles at 65,38 cycles at 60 \\
\hline & UNH148 & 2 cycles at 65,38 cycles at 57 \\
\hline & UNH995 & 2 cycles at 64,38 cycles at 60 \\
\hline & UNH104 & 2 cycles at 65,2 cycles at 56,36 cycles at 60 \\
\hline & GM258 & 2 cycles at 65,2 cycles at 60,36 cycles at 57 \\
\hline & UNH719 & 2 cycles at 64,38 cycles at 60 \\
\hline & UNH846 & 2 cycles at 65,38 cycles at 61 \\
\hline \multirow[t]{7}{*}{3} & GM354 & 2 cycles at 65,2 cycles at 60,36 cycles at 57 \\
\hline & GM271 & 2 cycles at 62,38 cycles at 60 \\
\hline & UNH971 & 2 cycles at 66,2 cycles at 63,36 cycles at 60 \\
\hline & GM150 & 2 cycles at 63,38 cycles at 58 \\
\hline & GM128 & 2 cycles at 64,38 cycles at 61 \\
\hline & GM526 & 2 cycles at 65,2 cycles at 63,36 cycles at 60 \\
\hline & UNH982 & 2 cycles at 65,2 cycles at 62,36 cycles at 60 \\
\hline \multirow[t]{8}{*}{23} & GM557 & 2 cycles at 65,2 cycles at 60,36 cycles at 57 \\
\hline & UNH848 & 2 cycles at 65,38 cycles at 61 \\
\hline & UNH197 & 2 cycles at 65,2 cycles at 56,36 cycles at 60 \\
\hline & GM597 & 2 cycles at 64,2 cycles at 60,36 cycles at 57 \\
\hline & UNH898 & 2 cycles at 65,38 cycles at 61 \\
\hline & UNH879 & 2 cycles at 64,38 cycles at 61 \\
\hline & GM576 & 2 cycles at 64,2 cycles at 62,36 cycles at 57 \\
\hline & UNH907 & 2 cycles at 66,38 cycles at 60 \\
\hline
\end{tabular}




\section{RESULTS}

\section{Proof of clonal nature}

Eighty seven microsatellite markers were successfully amplified. Analyses of the fragments after genotyping revealed that the clonal individuals (six broodstock with markers from LG1, 3 and 23; and three broodstock from the rest of the LGs) were homozygous at all of the loci concerned. The genotypes with markers from LG1, 3 and 23 are given in Table 4. Numbers of alleles from outbred individuals are also shown for predicting marker polymorphisms. Sixty seven markers were found to be polymorphic in outbred individuals.

\section{Sex ratios and viability in clonal lines}

The overall sex ratio result (at three months) obtained from 8 crosses involving all 6 clonal females showed that 105 of 106 progeny sexed were females. However, in almost all the crosses the number of offspring was small (ranging from 2 to 26). Table 5 presents the sex ratios from these crosses between clonal line females and neomales.

The viability of the offspring from clonal group is shown in Table 6 which shows mean survival rate of only $5.16 \%$ on day 11 (after yolk sac absorption period) significantly different $(P<0.05)$ from that in outbred males crossed with outbred females $(68.46 \%)$.

\section{Sex ratios involving clonal and outbred females with a range of males}

Table 7 shows and compares the sex ratios obtained from clonal females and outbred females when crossed with different types of male individuals. Correlation analysis of sex ratios obtained from paired (half-sib) crosses involving clonal and outbred females with a range of males (clonal line neomales, $X Y$ males and $Y Y$ males) was conducted.

The correlation coefficient between the sex ratios obtained from the clonal and outbred females was $0.994(P<0.01 ; n=8)$ (Figure 1). The chi-squared test statistics of the paired values of sex ratio did not differ significantly ( $P>0.05$, d.f 1 ) between clonal and outbred female sets.

Table 3. Inheritance of alleles in clonal line of females $(X X)$ with DNA markers from LG1, 3 and 23 of tilapia. No. of clonal females used $=6$; No. of outbred individuals $=6$

\begin{tabular}{|cccccc|}
\hline $\begin{array}{c}\text { Name of } \\
\text { markers (LG) }\end{array}$ & $\begin{array}{c}\text { Genotypes of } \\
\text { clonal females } \\
\text { and No. of } \\
\text { alleles in } \\
\text { outbred animals }\end{array}$ & $\begin{array}{c}\text { Name of } \\
\text { markers } \\
\text { (LG) }\end{array}$ & $\begin{array}{c}\text { Genotypes of } \\
\text { clonal females } \\
\text { and No. of } \\
\text { alleles in } \\
\text { outbred animals }\end{array}$ & $\begin{array}{c}\text { Name of } \\
\text { markers (LG) }\end{array}$ & $\begin{array}{c}\text { Genotypes of } \\
\text { clonal } \\
\text { females and } \\
\text { No. of alleles } \\
\text { in outbred } \\
\text { animals }\end{array}$ \\
\hline GM633 (1) & $206 / 206(3)$ & GM354 (3) & $142 / 142(2)$ & GM557 (23) & $268 / 268(2)$ \\
UNH985 (1) & $144 / 144(2)$ & GM271 (3) & $134 / 134(2)$ & UNH848 (23) & $208 / 208(2)$ \\
UNH931 (1) & $227 / 227(3)$ & UNH971(3) & $215 / 215(3)$ & UNH197 (23) & $205 / 205(2)$ \\
UNH213 (1) & $211 / 211(2)$ & GM150 (3) & $217 / 217(2)$ & GM597 (23) & $151 / 151(2)$ \\
GM201 (1) & $164 / 164(2)$ & GM128 (3) & $157 / 157(2)$ & UNH898 (23) & $286 / 286(2)$ \\
UNH148 (1) & $172 / 172(3)$ & GM526 (3) & $260 / 260(2)$ & UNH879 (23) & $238 / 238(2)$ \\
UNH995 (1) & $184 / 184(3)$ & UNH982(3) & $124 / 124(1)$ & GM576 (23) & $242 / 242(2)$ \\
UNH104 (1) & $147 / 147(3)$ & - & - & UNH907 (23) & $134 / 134(2)$ \\
GM258 (1) & $144 / 144(3)$ & - & - & - & - \\
UNH719 (1) & $127 / 127(3)$ & - & - & - & - \\
UNH846 (1) & $190 / 190(3)$ & - & - & - & - \\
WT1short (1) & $64 / 64(2)$ & - & - & & - \\
\hline
\end{tabular}

\section{DISCUSSION}

Some works on the verification of the gynogenetic clonal females (founders) are available. In a few cases, clonal lines have been validated using a small number of markers but studies using larger numbers of polymorphic microsatellite markers to verify clonal lines of females are lacking. 
We discuss the methods used by other authors to verify clonal females (founders as well as lines) and their outcomes followed by an interpretation of the results from the present study. The clonal status of the clone founders, the genetic uniformity of gynogenetic offspring from each clone founder and the genetic differences between clonal lines on DNA level in Nile tilapia other than the Stirling strain have been observed by using different DNA based techniques (Jenneckens et al., 1999), e.g., multilocus DNA fingerprinting, random amplified polymorphic DNA (RAPD) and simple sequence repeat-anchored PCR (SSRa-PCR). Multilocus DNA fingerprinting and RAPD demonstrated that carryover of male chromosomal DNA by the use of UV-irradiated sperm for induction of gynogenesis did not occur and that the clonal lines could be accurately distinguished from each other. However, the primers used in SSRa-PCR could not determine the absence of paternal genomic transmission due to a lack of visible informative paternal bands. In such cases, microsatellite markers could be advantageous because of their high information content.

Table 4. Sex ratios in crosses between clonal line females and neomales

\begin{tabular}{|c|c|c|c|}
\hline Neo $\sigma^{\lambda}{ }^{\lambda}$ & Clonalo우 & No. male (M) & No. female (F) \\
\hline \multirow[t]{2}{*}{00 068C FD8F } & 00 068C F2E0 & 0 & 22 \\
\hline & 00 068C D9B1 & 0 & 17 \\
\hline \multirow[t]{2}{*}{000633 E607 } & 00 068D 0073 & 0 & 12 \\
\hline & 000633 EA38 & 0 & 2 \\
\hline \multirow[t]{2}{*}{00 064D 1843} & 00 064E 4714 & 1 & 13 \\
\hline & 00 068C D6BE & 0 & 4 \\
\hline \multirow[t]{3}{*}{00 064C EBEE } & 00 068C D6BE & 0 & 26 \\
\hline & 00 064E 4714 & 0 & 9 \\
\hline & Total & 1 & 105 \\
\hline
\end{tabular}

Table 5. Viability studies in clonal line compared to outbred crosses

\begin{tabular}{|c|c|c|c|c|}
\hline \multicolumn{2}{|c|}{ Cross groups } & No. of eggs & $\begin{array}{r}\text { No. live on day } 4 \\
\text { (hatched fry) }\end{array}$ & $\begin{array}{r}\text { No. live on day } 11 \\
\text { (YSR fry stocked in } \\
\text { tanks) }\end{array}$ \\
\hline \multirow[t]{2}{*}{00 068C FD8F } & 00 068C F2E0 & 200 & $40(20 \%)$ & $35(17.5 \%)$ \\
\hline & 00 068C D9B1 & 200 & $20(10 \%)$ & $17(8.5 \%)$ \\
\hline \multirow[t]{2}{*}{000633 E607 } & 00 068D 0073 & 380 & $26(6.8 \%)$ & $12(3 \%)$ \\
\hline & 000633 EA38 & 100 & $2(2 \%)$ & $2(2 \%)$ \\
\hline \multirow[t]{2}{*}{00 064D 1843} & 00 064E 4714 & 200 & $18(9 \%)$ & $14(7 \%)$ \\
\hline & $00068 C$ D6BE & 150 & $4(2.6 \%)$ & $4(2.6 \%)$ \\
\hline \multirow[t]{2}{*}{00 064C EBEE } & 00 068C D6BE & 250 & $29(11.6 \%)$ & $26(10.4 \%)$ \\
\hline & 00 064E 4714 & 150 & $14(9.3 \%)$ & $10(6.67 \%)$ \\
\hline \multirow[t]{2}{*}{00 064D 0E7A } & $\begin{array}{l}00 \text { 068C F2E0 } \\
00 \text { 068C DD59* }\end{array}$ & $\begin{array}{l}350 \\
150\end{array}$ & $\begin{array}{l}0(0 \%) \\
0(0 \%)\end{array}$ & $\begin{array}{l}0(0 \%) \\
0(0 \%)\end{array}$ \\
\hline & & & Mean $\%=7.13 \pm 6.24$ & Mean $\%=5.767^{a}$ \\
\hline \multicolumn{5}{|c|}{ Clonal $\hat{\partial} \mathbf{x}$ Outbred $q \circ$} \\
\hline 00 068C FD8F & 000638 E8DD & 300 & $35(11.67 \%)$ & $32(10.67 \%)$ \\
\hline \multirow[t]{2}{*}{000633 E607 } & 000633 2FB5 & 250 & $55(22 \%)$ & $49(19.6 \%)$ \\
\hline & & & $\begin{array}{r}\text { Mean } \\
\%=16.84 \pm 7.30\end{array}$ & Mean $\%=15.135^{\mathrm{b}}$ \\
\hline \multicolumn{5}{|c|}{ Outbred $\widehat{\partial} \widehat{x}$ outbred $q q$} \\
\hline 00 068C FBE2 & 000633 2FB5 & 350 & NR & $240(68.57 \%)$ \\
\hline \multirow[t]{2}{*}{00 064C FEED } & 000638 E8DD & 300 & NR & $205(68.33 \%)$ \\
\hline & & & - & Mean $\%=68.45^{\mathrm{c}}$ \\
\hline
\end{tabular}

$P\left(X^{2} a, b\right)>0.05 ; P\left(X^{2} a, c\right)<0.05$, *this clonal female was not verified but was from same line; NR= Not recorded 
The use of allozyme markers to detect the variation, prior to the development of more reliable polymorphic markers (e.g., microsatellites or SNPs) has been quite common for assessing parental contribution and the genetic status of the progeny in all forms of ploidy manipulations. Heterozygous and homozygous clones for allozyme adenosine deaminase $\left(A D A^{*}\right)$ were produced using reproductively viable mitotic gynogenetic fish by Hussain et al. (1998) in Stirling population. Eggs from a female heterozygous at the $A D A^{*}$ locus for 135/113 alleles were fertilized with UV irradiated sperm in early and late pressure shock treatment (Hussain et al., 1991, 1993). Mitotic gynogens were reared to sexual maturity. Two female homozygous for the $113 A D A^{*}$ allele obtained in the study were used to produce meiotic gynogens or inbred clones, ICL, and outbred clones, OCL. The use of the $A D A^{*}$ marker enabled both clones to be identified and confirmed that there was no paternal inheritance in the ICL produced by gynogenetic reproduction. All of the outbred clonal progeny $(\mathrm{N}=80)$ were heterozygous $(113 / 135)$ and all of the inbred clonal progeny $(\mathrm{N}=7)$ were homozygous at $A D A^{*}$ locus. Sarder et al. (1999) studied the same isozyme locus $A D A^{*}$ genotypes of control and gynogenetic progeny from experiments in which $O$. niloticus females (genotype 113/135) and an O. aureus males (genotype 138/138) were used as parents. The absence of the male parent's genotype in gynogenetic offspring was an evidence of successful gynogenesis. The ability to study a large number of variable allozyme loci has also been particularly useful in estimating the frequency of heterozygotes in meiotic gynogenesis and thereby the level of recombination that has occurred at the first meiotic division (reviewed by Seeb and Miller, 1990). In contrast to the EST-2* locus where there was no evidence of any recombinant genotypes $(y=0.00)$ in any of the meiotic gynogenetic offspring $(N=150)$ (and hence suggests the $E S T-2^{*}$ locus is very close to its respective centromere) the results for the $A D A^{*}$ locus suggested that it was placed distally on a chromosome arm.

Microsatellite markers are co-dominant and frequently show polymorphism (heterozygosity) in individuals. Therefore they are more appropriate than allozyme markers (codominant markers) or AFLPs (dominant markers) in analyzing the products of chromosome set manipulations, for example, clonal gynogenetic lines of females. Polymorphic microsatellite loci were investigated in several gynogenetic families and clonal progeny of Nile tilapia by Ezaz et al. (2004b) to verify gynogenesis and clonal lines. They worked with 6 microsatellite markers in two meiotic gynogenetic families in selected loci with high gene-centromere recombination rates, which could be used to discriminate meiotic from mitotic gynogenetics. Microsatellite loci UNH189 and UNH211 showed $96.7 \%$ and $92.0 \%$ heterozygosity, respectively and thus indicated very low probability of an individual meiotic gynogenetic being homozygous for both loci. Polymorphic microsatellite loci were also used successfully to verify maternal inheritance in gynogenetic populations of African catfish and European sea bass by Galbusera et al. (2000) and Peruzzi and Chatain (2000). Genotyping of clonal line gynogenetic females in our current study with a moderately large number of microsatellite DNA markers showed that the representative sample of females from the clonal line were homozygous at all of the 89 microsatellite loci. The verification of this fully inbred clonal nature strengthens the hypothesis that this 'pure inbred' females can be validated as a 'reference line' for sex ratio studies in Nile tilapia to whom various types of males (e.g., putative $X Y$ and $Y Y$ males as well as $\mathrm{XX}$ neomales) can be crossed. In a predicted predominantly $\mathrm{XX}-\mathrm{XY}$ sex determining mechanism, the male parents to whom the reference line of females are crossed will be identified as the 'hypothetical indicators' for any genetic variation inherited, and any unexpected sex ratios observed in progeny sex. Such experiments are ideal to resolve the ambiguity if the female (parental) genetic components may also play a role in genetic variation affecting sex ratios in progeny. For example, Guan et al. (2000) suggested that female Nile tilapia may have a greater influence than males on variation of sex ratios because of the presence of two sex determining genes in tilapia that appeared to be different versions of the 'doublesex' gene first described in Drosophila. Drosophila has only one doublesex gene, and produces male and female products by RNA splicing after transcription. One of these genes is known to express in vertebrate testis (including Zebrafish). Tilapia has a variant of the same gene and is reported to express in ovaries (thereby known as female version of 'doublesex'). The expression of two doublesex genes is often mutually exclusive and therefore, it is anticipated additional genes or environmental factors may also control the expression of sex in this species. The use of a validated clonal line of females in such cases limits the parental influence on sex ratios where interpretation on such sex determinants is complex, by acting as 'control' individuals. 
The viability of clonal female offspring was found to be low (Table 6). One popular explanation behind such viability is that these low and variable survival rates are caused by expression of deleterious genes and inbreeding depression. In theory, double haploid clone founders produced by androgenesis or gynogenesis should suffer from inbreeding depression due to the expression of homozygous deleterious mutations (Purdom et al., 1985). Many of these mutations could act during early embryo development, thereby causing a significant reduction in survival of double haploid fry. Assuming an average genetic load of 1-2 harmful recessive genes for any female parent, the mortality in her doubled haploid progeny could be as high as $50-75 \%$ (Komen and Thorgaard, 2007). Müller-Belecke and Hörstgen-Schwark (2000) obtained survival of clonal line females at first-feeding varying between 1 and $20 \%$ in comparison to about $45 \%$ in controls. Sarder et al. (1999) obtained mean survival rates of $63.11 \pm 6.41 \%, 30.89 \pm 6.30 \%$, and $4.34 \pm 1.24 \%$ respectively at yolk sac resorption in diploid control, meiotic gynogenetic, and mitotic gynogenetic groups of $O$. niloticus. In zebrafish, gynogenesis was used to identify 14 recessive maternal effect mutations. Homozygosity for these mutations in adult females led to the inviability of their offspring (Pelegri et al., 2004). As homozygous animals show inbreeding depression, it is likely that the performance of homozygous clones in terms of viability and fertility usually follows that of the parent from which they were derived. The offspring derived from the clonal line of females (produced from mitogynes) in this study may have deleterious genes fixed which have caused poor fertility of germ cells.

Analysis of sex ratio results obtained from 8 crosses involving all 6 clonal females and 4 neomales in this study confirms sex ratios very close to all-female (99.1\%). This result supports earlier results (Sarder et al., 1999; Ezaz et al., 2004b) in producing nearly all female progeny in mitotic gynogenetic clonal lines. All female meiogynes $(\mathrm{N}=89)$ were observed by Penman et al. (1987) whereas a little portion of males (eight among 187 meiogynes) was evident (Mair et al., 1991a). They suggested that the occurrence of males in gynogenetics may result from sex reversal mechanism develops from homozygosity of rare autosomal, recessive, sex-influencing genes. Sarder et al. (1999) observed presence of males in all of four mitogyne groups and in three out of four meiogyne groups. However while observing sex ratios in gynogenetic inbred clonal lines of Nile tilapia, they obtained only females in the lines except one.

The presence of fairly high proportions of males in both meiogyne and mitogyne groups is explained by the action of an epistatic locus causing sex reversal from female to male under homozygous condition (Hussain et al.,1994; Komen et al., 1992, 1995). Thus a female that is heterozygous at this locus (XX SRsr) would be expected to produce non-recombinant homozygous males (XX srsr) and both non-recombinant and recombinant females (XX SRSR and XX SRsr respectively) in meiotic gynogenesis and only XX srsr males and XX SRSR females in mitotic gynogenesis. Müller-Belecke and Hörstgen-Schwark (1995) reported $35.3 \%$ male progeny in the mitogynes of $O$. niloticus. They suggested the occurrence of two or more minor sex determining factors, which are able to override the XX-XY mechanism when they act in combination and occur in homozygous state might account for the sex ratios observed. They also interpreted in another way that the genotype exhibits greater instability in sex differentiation, perhaps through greater susceptibility to environmental effects.

Following the discussion and based on the assumption of locus polymorphism (autosomal or sex-determining locus) in (many) outbred females for determination of sex in Nile tilapia, an interpretation on occurrence of progeny sex can be done on the basis of meiotic gynogenesis, mitotic gynogenesis and clonal line individuals produced from mitotic gynogens. As an example, if the female parent is $X X$ but heterozygous for a hypothetical recessive autosomal sex reversal locus $(\mathrm{SR} / \mathrm{sr})$, meiotic gynogenesis will result in $X X, S R / S R$ and $X X, S R / s r$ genotypes consisting of females and $X X$, sr/sr consisting of male and/or females depending on the penetrance and position of the locus. Mitotic gynogenesis will produce XX, SR/SR (only females) or XX, sr/sr (males and/or females depending on the penetrance) and occurrence of more males may be apparent. In producing clonal line of females, these mitotic males are eliminated (since they are not used as clone founders). A clonal line of nearly all females founded from mitotic female clone founders (e.g., the outcome of the present study) thereby could hypothetically account for a strong selection against the sex reversal allele (sr/sr) with strong penetrance. 
The homozygous nature of the clonal line females in this study with good number of microsatellite markers, the yield of very close to $100 \%$ female progeny with sex-reversed neomales suggests that this line of clonal females could be used as standard, 'reference line' for genomics, sex determination and other studies in Nile tilapia.

\section{ACKNOWLEDGEMENTS}

This study was supported by Commonwealth Scholarship Commission (CSC reference BDCS07-28). We also thank Mr Keith Ranson and William Hamilton for providing facilities for experimental fish in TAF.

\section{REFERENCES}

1. Trevarrow B and B Robinson, 2004. Genetic Backgrounds, Standard Lines, and Husbandry of Zebrafish. Methods in Cell Biology, 77: 599-616.

2. Dunham RA, 2004. Aquaculture and Fisheries Biotechnology: genetic approaches. CABI. ISBN 085199-596-9.

3. Komen $\mathrm{H}$ and $\mathrm{GH}$ Thorgaard, 2007. Androgenesis, gynogenesis and production of clones in fishes: $\mathrm{A}$ review. Aquaculture, 269: 150-173.

4. Kocher TD, W-J Lee, H Sobolewska, DJ Penman and BJ Mcandrew, 1998. A genetic linkage map of a cichlid fish, the tilapia (Oreochromis niloticus). Genetics, 148: 1225-1232.

5. Purdom CE, 1969. Radiation-induced gynogenesis and androgenesis in fish. Heredity 24, 293-296.

6. Nace GW, CW Richards, JH Jr. Asher, 1970. Parthenogenesis and genetic variability I: linkage and inbreeding estimations in the frog Rana pipiens. Genetics, 66: 349-368.

7. Allendorf FW and RF Leary, 1984. Heterozygosity in gynogenetic diploids and triploids estimated by gene-centromere recombination rates. Aquaculture, 43: 413-420.

8. Hussain MG, BJ McAndrew, DJ Penman and P Sodsuk, 1994. Estimating gene-centromere recombination frequencies in gynogenetic diploids of Oreochromis niloticus L., using allozymes, skin colour and a putative sex-determining locus (SDL-2). In: Genetics and Evolution of Aquatic Organisms (ed. by A.R. Beaumont), pp. 502-509. Chapman and Hall, London.

9. Hussain MG, DJ Penman, BJ McAndrew, 1998. Production of heterozygous and homozygous clones in Nile tilapia. Aquaculture International, 6: 197-205.

10. Zhang $\mathrm{XL}$ and $\mathrm{H}$ Onozato, 2004. Hydrostatic pressure treatment during the first mitosis does not suppress the first cleavage but the second one. Aquaculture, 240: 101-113.

11. Müller-Belecke A and G Hörstgen-Schwark, 1995. Sex determination in tilapia (Oreochromis niloticus) sex ratios in homozygous gynogenetic progeny and their offspring. Aquaculture: 137: 5765.

12. Sarder MRI, DJ Penman, JM Myers, BJ McAndrew, 1999. Production and propagation of fully inbred clonal lines in the Nile tilapia (Oreochromis niloticus L.). Journal of Experimental Zoology, 284: 675685.

13. Ezaz MT, S Sayeed, BJ McAndrew and DJ Penman, 2004b. Use of microsatellite loci and AFLP markers to verify gynogenesis and clonal lines in Nile tilapia Oreochromis niloticus L. Aquaculture Research, 35: 1472-1481.

14. Wayne ML and LM Mclntyre, 2002. Combining mapping and arraying: an approach to candidate gene identification. Proceedings of the National Academy of Sciences, 99: 14903-14906.

15. Liu Z, 2007. Sequencing the genome. In: Aquaculture genome technologies (Part IV: Preparing for genome sequencing) (ed. By Z. Liu), pp. 475-488. Blackwell publishing, lowa, USA.

16. Galbusera P, FAM Volckaert and F Ollevier, 2000. Gynogenesis in the African catfish Clarias gariepinus (Burchell, 1822) III. Induction of endomitosis and the presence of residual genetic variation. Aquaculture, 185: 25-42.

17. Nagy A, K Rajki, L Horvath and V Csanyi, 1978. Investigation on carp Cyprinus carpio gynogenesis. Journal of Fish Biology, 13: 215-224. 
18. Don $\mathrm{J}$ and $\mathrm{RR}$ Avtalion, 1988. Production of $\mathrm{F}_{1}$ and $\mathrm{F}_{2}$ diploid gynogenetic tilapias and analysis of the Hertwig curve obtained using ultraviolet irradiated sperm. Theoretical and Applied Genetics, 76: 253259.

19. Varadaraj K, 1990. Dominant red colour morphology used to detect contamination in batches of Oreochromis mossambicus (Peters) gynogens. Aquaculture and Fisheries Management, 21:163-172.

20. Myers JM, DJ Penman, Y Basavaraju, SF Powell, P Baoprassertkul, KJ Rana, N Bromage and BM McAndrew, 1995. Induction of diploid androgenetic and mitotic gynogenetic nile tilapia (Oreochromis niloticus L.). Theoretical and Applied Genetics, 90: 205-210.

21. Ezaz MT, SC Harvey, C Boonphakdee, AJ Teale, BJ McAndrew and DJ Penman, 2004a. Isolation and physical mapping of sex-linked AFLP markers in Nile tilapia (Oreochromis niloticus L.). Marine Biotechnology, 6: 435-445.

22. Carter RE, GC Mair, DOF Skibinski, DT Parkin and JA Beardmore, 1991. The application of DNA fingerprinting in the analysis of gynogenesis in tilapia. Aquaculture, 95, 41-52.

23. Volckaert FAM, PHA Galbusera, BAS Hellemans, C Van den Haute, D Vanstaen and F Ollevier, 1994. Gynogenesis in the African catfish (Clarias gariepinus): I. Induction of meiogynogenesis with thermal and pressure shocks. Aquaculture, 128: 221-223.

24. Felip A, G Martinez-Rodriguez, F Piferrer, M Carrillo, S Zanuy, 2000. AFLP analysis confirms exclusive maternal genomic contribution of meiogynogenetic sea bass (Dicentrarchus labrax L.). Marine Biotechnology, 2: 301-306.

25. Jenneckens I, A Müller-Belecke, G Hörstgen-Schwark and J Meyer, 1999. Proof of the successful development of Nile tilapia (Oreochromis niloticus) clones by DNA fingerprinting. Aquaculture, 173: 377-388.

26. Peruzzi S and B Chatain, 2000. Induction of Tetraploid Gynogenesis in the European Sea Bass (Dicentrarchus labrax L.). Genetica, 119: 225-228.

27. Vignal A, Milan A, SanCristobal M, Eggen A. (2002). A review on SNP and other types of molecular markers and their use in animal genetics. Genetics Selection Evolution, 34, 275-305.

28. Lee BY, WJ Lee, JT Streelman, KL Carleton, AE Howe, G Hulata, A Slettan, JE Stern, Y Terai and TD ocher, 2005. A second-generation genetic linkage map of tilapia (Oreochromis spp.). Genetics, 170: 237-244.

29. Lee BY, DJ Penman and TD Kocher, 2003. Identification of a sex-determining region in Nile tilapia (Oreochromis niloticus) using bulked segregant analysis. Animal Genetics, 34: 379-383.

30. Lee BY, G Hulata and T Kocher, 2004. Two unlinked loci controlling the sex of blue tilapia (Oreochromis aureus). Heredity, 92: 543-549.

31. Shirak A, E Seroussi, A Cnaani, AE Howe, R Domokhovsky, N Zilberman, TD Kocher, G Hulata and M Ron, 2006. Amh and Dmrta2 genes map to tilapia (Oreochromis spp.) linkage group 23 within quantitative trait locus regions for sex determination. Genetics, 174: 1573-1581.

32. Hussain MG, A Chatterji, BJ McAndrew and R Johnstone, 1991. Triploidy induction in Nile Tilapia, Oreochromis niloticus L. using pressure, heat and cold shocks. Theoretical and Applied Genetics, 81: 6-12.

33. Hussain MG, DJ Penman, BJ McAndrew and R Johnstone, 1993. Suppression of first cleavage in the Nile tilapia, Oreochromis niloticus L. - a comparison of the relative effectiveness of pressure and heat shocks. Aquaculture, 111: 263-270.

34. Seeb JE and GD Miller, 1990. The integration of allozyme analyses and genomic manipulations for fish culture and management. In: Electrophoretic and isoelectric focusing techniques in fisheries management (ed. By Whitmore, D.H.), pp. 265-280, CRC press, Boca Raton, USA.

35. Guan G, T Kobayashi and Y Nagahama, 2000. Sexually dimorphic expression of two types of DM (Doublesex/mab-3)-domain genes in a teleost fish, the tilapia (Oreochromis niloticus). Biochemical and Biophysical Research Communications, 272: 662-666.

36. Purdom CE, D Thompson and YD Lou, 1985. Genetic engineering in rainbow trout, Salmo gairdneri R., by suppression of meiotic and mitotic metaphase. Journal of Fish Biology, 27: 73-79.

37. Müller-Belecke A and GHörstgen-Schwark, 2000. Performance testing of clonal Oreochromis niloticus lines. Aquaculture, 184: 67-76. 
38. Pelegri F, MPS Dekens, SS Merker, HM Maischein, C Weiler and CN Volhard, 2004. Identification of recessive maternal-effect mutations in the zebrafish using a gynogenesis-based method. Developmental Dynamics, 231: 324-335.

39. Penman DJ, MS Shah, JA Beardmore and DOF Skibinski, 1987. Sex ratios of gynogenetic and triploid tilapia. In: Proc. World Symp. Selection, Hybridisation and Genetic Engineering in Aquaculture (ed. By K. Tiews), 20-27 May 1986, Bordeaux, Vol II, pp. 267-287.

40. Mair GC, AG Scott, DJ Penman, JA Beardmore and DOF Skibinski, 1991. Sex determination in the genus Oreochromis: 1. Sex reversal, gynogenesis and triploidy in O. niloticus (L.). Theoretical and Applied Genetics, 82: 144-152.

41. Komen J, M Yamashita and Y Nagahama, 1992. Testicular development induced by a recessive mutation during gonadal differentiation of female common carp (Cyprinus carpio L.). Development, Growth and Differentiation, 34: 535-544.

42. Komen J, JGD Lambert, CJJ Richter and HJT Goos, 1995. Endocrine control of sex differentiation in $\mathrm{XX}$ female, and in XY and XX male common carp (Cyprinus carpio L.). In: Proceedings of the Fifth International Symposium on the Reproductive Physiology of Fish (ed. by F.W Goetz \& P. Thomas), 2-8 July, The University of Texas in Austin, TX, USA, 383p. 